\title{
The Production of Knowledge in Different Sectors: a model and some hypotheses
}

\author{
DOMINIQUE FORAY \\ Centre for Education, Research and Innovation, OECD, Paris, France \\ DAVID HARGREAVES \\ Wolfson College, Cambridge, UK
}

ABSTRACT We develop a model that supports the rapid production and accumulation of knowledge in different sectors. The model combines two dimensions: the first is the mode of knowledge production, either scientific or humanistic; and the second concerns the strength of knowledge spillovers, generated by competition and/or cooperation. The model is then applied to the knowledge base in different sectors. The contrasting historical trajectories of knowledge production and dissemination in medicine and education in England are examined in the light of the continuing debate about the nature of educational research and the role of teachers within it.

\section{What are the New Challenges Facing the Knowledge Economy Today?}

While knowledge has always been at the heart of economic development, there is evidence that the capacity to produce and use knowledge has more explanatory value in explaining current levels of economic welfare or rates of growth. Factors determining the success of firms and national economies are more dependent than ever on the capacity to produce and use knowledge. As a result, innovation and technological changes have become more central to economic performance (Foray \& Lundvall, 1996; OECD, 2000).

This tendency does not affect the whole economy in the same way: an unbalanced and uneven production of knowledge across sectors and fields can be observed. Advances in human know-how have been spectacular in some sectors such as ICTs and parts of medicine, but very limited in areas such as education, management and urban development (Nelson, 1999). A major policy concern is to understand the factors accounting for such uneven development and to devise a strategy to close the gap between sectors with different rates of knowledge accumulation processes. The education sector, in contrast with some other sectors like transport or biotechnology, is characterised by relatively slow knowledge production and dissemination.

So the question we ask above may be clarified by comparisons between sectors and their very different social and economic institutions. Is it fair to compare the process of knowledge production between sectors allocating huge resources to R\&D and sectors in which knowledge production is funded far less generously? Is it acceptable to compare industrial activities based on a rich corpus of scientific knowledge with people-centred 
professions in which the production of scientific knowledge and the construction of predictive models are difficult to achieve? Such a comparison risks neglecting the specific nature of both cognitive processes and socio-economic institutions operating in different sectors.

We suggest, however, that this sectoral comparison introduces a promising line of analysis and research. Investigations of a selection of sectors may reveal some regularities and constants in terms of the properties of knowledge and the kinds of socio-economic institution that can be relied upon to produce and apply knowledge.

Knowledge has several properties that economists identify as those characterising the general class of 'public goods'. Because it is a public good, there are considerable benefits when it is shared. Knowledge is not depleted by intensive use but instead is likely to be enriched the more that individuals are allowed to access, use and improve it. Knowledge is often produced in activities in which other motivations are dominant. This process of 'learning-by-doing' occurs within many contexts of manufacturing products, providing a service or using equipment. Knowledge is 'sticky', i.e. difficult and costly to transfer from one site to another, especially where it is highly tacit rather than explicit and codified.

\section{Why is There Unbalanced Production of Knowledge Across Sectors and Fields?}

Two factors are important in shaping the way knowledge is produced and accumulated. One factor concerns the cognitive dimension: how is knowledge produced and advanced from a cognitive point of view and what is the cognitive method for determining best practice? We propose two 'modes' (Gibbons et al., 1994) that we call the 'science-in-technology (or S-i-T) mode' and the 'humanistic mode'.

The first is based on robust and systematic relations between science and technology, 'a strong science that illuminates technology' (Nelson, 1999). Scientific knowledge is of direct value to the rapid development of innovative processes and products. It is characterised by:

- experimentation in the production of knowledge;

- strong linkages and feedback loops between the production of scientific knowledge and the advance of technology;

- processes of invention taking place 'off-line' in R\&D laboratories; and

- a knowledge base codified in instructional guides and documents, permitting easy transfer from science to technology.

In this mode of knowledge production, the ability to conceive and carry out well-defined and controlled experimental ways of improving technological performance is crucial.

In other sectors, however, the main source of knowledge production takes the form of 'learning-by-doing', where individuals learn as they go along, assess what they learn and hone their practices over time. Such learning occurs 'on line' - in the plant, on site, in the classroom, as opposed to 'off-line' R\&D based in workshops and laboratories. We call this the 'humanistic' mode of knowledge production. Here R\&D, as usually defined, is not of immediate value for developing practical applications. Advances in know-how depend not on scientific progress but on the ability to exploit the opportunities for learning-by-doing, which are related to the situated character of learning-by-doing (Tyre \& von Hippel, 1997). The physical context, as well as the interactions between people and physical equipment or between the service provider and the client, may all create cognitive opportunities for learning. Constraints come from the need to maintain the regular activity. Knowledge production may be the by-product of the activity rather than its intentional goal. There is, therefore, a tension between normal performance and learning. The expertise thus produced 
does not constitute scientific knowledge in the sense of the S-i-T mode, and the locus of the learning process is not the R\&D laboratory. When such learning-by-doing opportunities are well exploited, knowledge production can flourish. However, know-how advances are usually slower than in the S-i-T mode.

The two modes also differ in the way knowledge is disseminated. Scientific knowledge is mainly explicit and codified and thus easily transmitted via books and journals. Much humanistic knowledge is tacit and so requires interpersonal interactions, such as coaching and mentoring, if it is to be transferred (Eraut et al., 1998). Furthermore, the organisation of scientific research is characterised by strong incentives for the rapid dissemination of knowledge, encouraged by a competitive reward system based upon accepted claims to priority of discovery or invention (see Dasgupta \& David, 1994, for an economic analysis of the institution of open science).

In our view no sector in practice relies exclusively on one mode. Even the most sciencebased sectors, such as biotechnology, derive some new knowledge from learning-by-doing. In the same way people-centred professions that strongly rely on the humanistic mode may also benefit from scientific knowledge: doctors build up their expertise through a combination of science-generated, explicit knowledge with their own learning-by-doing expertise from the routine exercise of their profession with their patients. Of course there are strong variations between sectors in the relative weight of the two modes.

A second set of factors governing the speed and rate of knowledge production is the importance and magnitude of knowledge spillovers: any original and valuable knowledge that becomes publicly accessible and is absorbed by individuals or groups other than the originator (Appleyard, 1996). The existence of knowledge spillovers is a sine qua non for increasing innovative opportunities. Wider dissemination of knowledge and timely, inexpensive access to new findings reduce wasteful duplication of research efforts; and putting information into the hands of a more diverse population of researchers increases the probability that useful new ideas will arise from novel combinations. Thus knowledge spillovers are crucial to the evolution of knowledge in all sectors (David \& Foray, 1995). Knowledge spillovers may increase through two channels: competition and cooperation.

Competition influences the level of involuntary spillovers. Competition not only creates incentives to produce new knowledge but it also forces the other agents to increase their own performance, through imitation or absorption of knowledge produced elsewhere, in order to avoid exclusion from the market. This encourages economic agents to develop absorptive capacities so that involuntary information and knowledge spillovers increase at the system level. In sectors that are not fully part of the market, such as education, the dissemination of knowledge is less automatic and administrative measures or 'reforms' aimed at disseminating knowledge and practices will have less impact than competitive markets. Involuntary knowledge spillovers are considerably more significant in competitive sectors of the economy.

Cooperation influences the level of voluntary spillovers; that is, it creates incentives that can motivate people to reveal their knowledge to others freely (see Harhoff et al., 2000; Allen, 1983). Case studies show that sectors rich in spillovers combine competition and cooperation (see Cockburn \& Henderson, 1997, for pharmaceuticals; and Appleyard, 1996, for semi-conductors).

Our model for the knowledge base in different sectors thus combines two dimensions, the mode of knowledge production and the strength of spillovers, yielding four cells with illustrative cases (Figure 1).

Such a representation does not claim to describe in detail those institutions and practices supporting the production and distribution of knowledge in a sector. The aim, rather, is to indicate the dominant characteristics in the sector's knowledge base as they affect the rate 


\begin{tabular}{|l|l|l|}
\hline Knowledge spillovers & $\begin{array}{l}\text { Strong spillovers } \\
\text { (competition and/or } \\
\text { cooperation generate } \\
\text { incentives to capture or to } \\
\text { reveal knowledge) }\end{array}$ & $\begin{array}{l}\text { Weak spillovers } \\
\text { (lack of competition or } \\
\text { cooperation generates } \\
\text { disincentives to capturing or } \\
\text { sharing knowledge) }\end{array}$ \\
\hline $\begin{array}{l}\text { S-i-T mode } \\
\text { science is in a predictive } \\
\text { stage, formal R\&D is } \\
\text { crucial and knowledge is } \\
\text { highly codified) }\end{array}$ & $\begin{array}{l}\text { Biotechnology, Chemicals, } \\
\text { Transport Technologies }\end{array}$ & Defence equipment \\
\hline $\begin{array}{l}\text { Humanistic mode } \\
\text { (learning-by-doing is the } \\
\text { key process, formal R\&D is } \\
\text { of secondary importance } \\
\text { and knowledge is poorly } \\
\text { articulated) }\end{array}$ & Consulting activity & $\begin{array}{l}\text { Education (primary school) } \\
\text { Early 19th century medicine }\end{array}$ \\
\hline
\end{tabular}

Figure 1. Four types of sectoral knowledge base

of knowledge production and dissemination. The upper row contains cases in which R\&D is a key pillar of the knowledge production system. Deliberate, formal efforts to produce robust knowledge are taken seriously by entrepreneurs and decision-makers, as the source of essential innovation. In these situations, companies and institutions are eager to make links to scientific networks, which are powerful mechanisms for maximising knowledge. The lower row contains cases in which the relation between research and the production of goods and services is of secondary importance and in which the lack of codification impedes the dissemination of knowledge. The left column contains areas where, as a result of competition, knowledge spillovers are important and determine the growth of a 'knowledge infrastructure'. The right column covers the opposite case, where there is low competition and fewer spillovers.

In the upper left cell are sectors where the S-i-T mode works well, with a high degree of spillover, leading to a rapid rate of innovation and advance in know-how. By contrast, in the lower right cell are sectors in which the science-technology interface does not operate and knowledge spillovers are weak, so a much slower process of knowledge is hypothesised.

Performance in these cases is dependent on effective organisational structures and knowledge management practices to compensate for the absence of the classical incentives of competition or cooperation that maximise information spillovers and knowledge dissemination.

It cannot be assumed that there is consensus in a sector about the nature of its knowledge base. At any one point a sector may contain competing knowledge bases, though one of them may eventually become dominant and displace or marginalise the others.

A sector may be taken to constitute a community of practice (Lave \& Wenger, 1991; Wenger, 1998). The community has a domain-specific knowledge base that both guides practice and makes sense of the community's heritage. Medical doctors, schoolteachers, aeronautical engineers and other kinds of professional community may be treated as examples of communities of practice. Such professional communities of practice, or sections of them, reflect what Knorr-Cetina (1999) calls epistemic cultures that produce and warrant knowledge. All communities of practice have a positive orientation to 'best practice' — which may be 
something preserved in the community's traditions as a standard to which practitioners aspire, or something yet to be identified. The methodology a community adopts to determine best practice within its domain will reflect its dominant epistemic culture. An epistemic culture can thus be defined as a means of identifying best practice.

A prime example of an epistemic culture is science. Different communities of practicephysicists, chemists or biologists - may nevertheless subscribe to the shared epistemic culture of science. Other professional communities of practice may be differentiated into sub-communities that subscribe to different epistemic cultures. Most industrial sectors are shifting quite rapidly towards the scientific epistemic culture, which is displacing rivals. This is the case in medicine, which is now dominated by the epistemic culture of science, with a smaller 'alternative medicine' community that adheres to the culture of humanism. The social sciences are notoriously divided between the two major epistemic cultures - the Naturwissenschaften and the Geisteswissenschaften. Within anthropology, for example, the physical anthropologists are orientated to the scientific epistemic culture, whereas social anthropologists are orientated to an interpretative version of social science, though this is challenged (Sperber, 1996; Plotkin, 2002).

\section{Why is the Education Sector Traditionally Characterised by a Slow Production of Knowledge?}

Consider the efforts to develop more effective educational practices in schools. Nelson (1999) has argued that this sector is characterised by a slow process of knowledge production about teaching and that teachers' knowledge has changed little in a hundred years. This is an exaggerated claim (see Teddlie \& Reynolds, 2000), but few would deny that knowledge production here has indeed been very slow and there are acknowledged difficulties in diffusing new or 'superior' knowledge.

Knowledge production in this sector is dominated by the humanistic mode of learningby-doing; the S-i-T mode is much weaker; competition between practitioners and institutions is relatively low and there are in consequence few knowledge spillovers. Substantial evidence collected and presented in OECD/CERI (1999) shows that the sciencetechnology interface is problematic and dissemination of innovation does not work well in the education sector. In this section, we describe the structure and dynamics of the professional knowledge base within the education sector (Hargreaves, 1999a, 1999b, 1999c). This evidence is analysed under three aspects:

- Formal R\&D is of secondary importance. The capacity and willingness to conduct educational experiments are limited, so many potential benefits of research into learning are not exploited.

- Most of the teachers' practical knowledge remains tacit, so the low level of knowledge codification inhibits the accumulation of know-how.

- There is much innovation, though little formal R\&D. Two factors limit the economic value of those innovations. Linkages and feedback between formal R\&D and professional practices are weak so that the practical knowledge of innovative practitioners is rarely drawn upon by professional researchers; and due to low levels of competition and collaboration, information spillovers and the dissemination of innovation are weak.

Formal R\&D is of secondary importance in education: certainly educational R\&D is unlike industrial or biomedical $R \& D$, i.e. generating knowledge of immediate value for solving problems and developing applications. One explanation (Nelson, 1999) might be the limited ability or willingness to conduct educational experiments to provide reliable guides to improve teaching practices. Moreover, what is reported to work in one school or test site 
has been hard to duplicate outside of the locus of the original research. It is thus argued that one of the basic conditions of the S-i-T mode simply does not work here. Other factors and impediments are involved. One is simply the lack of funding. Many teachers are willing in principle to do research, and to do so in partnership with universities, but they lack the resources to pay for the substitute or additional teachers needed to release them for classroom duties. As emphasised by Hegarty (1999), total expenditure on educational research in the UK is estimated at $£ 50-60$ million per year, while R\&D expenditure in the pharmaceutical industry is about $£ 2$ billion. Moreover in a period when central government is often accused by teachers of excessive regulation and control, the profession may become risk-averse and so inhibit the creation of a more experimental culture.

A second impediment is the failure to reshape the profession to adjust how teachers work in classrooms. Teachers spend much of their time in school on tasks that could be done efficiently and effectively only by non-teachers. By contrast, doctors learn to delegate much of their work - the minor ailments that are easy to treat, or some specialised tasks - to trainee doctors, nurses or other para-medical staff. By delegating more to assistants, teachers could reserve to themselves the more important educational problems that require highlevel skills, experience and judgement.

That many teachers lack either the qualifications and/or the confidence to engage in research is yet another impediment. There is now a significant pool of potential researchers among teachers, namely those who have undertaken a higher degree in education, which often includes research training and some practical research experience. With more support such teachers could continue with some research and quickly establish the principle of the teacher-researcher. There is the question of how small-scale studies can be coordinated so that they add up to a robust set of findings that have accumulated over time. Much educational research that is methodologically sound depends on either a very small sample and/or very specific and restricted contexts. As a result, these small studies cannot be a trustworthy basis for wider application and dissemination.

Some scientific purists might argue that a truly scientific knowledge base in education requires more randomised controlled trials (RCTs). Whilst appropriate techniques are available, and there exist some ardent advocates for RCTs in education (Fitz-Gibbon, 2001), there are few such studies. Moreover, much basic scientific research dealing with promising scientific areas, such as the neuro-sciences or cognitive psychology, is likely to be conducted in university faculties of psychology rather than education. Schools of education often have tenuous links with psychology departments, so their access to the knowledge frontier in cognitive psychology is limited. This creates problems for the dissemination of new knowledge into initial teacher training and the continuing professional development of teachers.

This absence of technical language is critical in explaining a lack of knowledge codification (Cowan et al., 1999) and this certainly applies to teachers' everyday talk, as Jackson (1968) has observed. The tacit state of practitioner knowledge is also critical in explaining the difficulties and impediments to knowledge production and dissemination in education. There is no more than a weak equivalent in the field of pedagogical knowledge to the systematic recording and widespread use of cases found in surgery and law and the physical models in engineering and architectural practice. Such records, coupled with comments and critiques of experts, allow new generations to pick up where earlier ones left off. By contrast

the beginner in teaching must start afresh, uninformed about prior solutions and alternative approaches to recurring practical problems. What student teachers learn about teaching, then, is intuitive and imitative rather than explicit and 
analytical; it is based on individual personalities rather than pedagogical principles. (Lortie, 1975)

Low levels of codification in the education sector make it difficult to produce 'learning programmes' or codified instructions that can be commented on and added to by practitioners. Teachers in regular classrooms tend to develop their own classification systems and rules of evidence.

Primary education is a sector where forms of 'learning-by-doing' are the main mechanism for generating knowledge. As Huberman (1992) observed, teachers are primarily artisans, working alone in a personally designed environment where they develop most of their skills by trial-and-error 'tinkering'. An interesting parallel with doctors can be considered. Primary education and health care are sectors where forms of 'tinkering' are an important mechanism for generating knowledge. Whatever science might contribute to their practice, both doctors and teachers have to exercise considerable professional judgement in making their higher-level decisions; they have to 'read' both client and context and be prepared to adapt their treatment until they find something that 'works' with the client, whether patient or pupil. In short, they learn to tinker, searching pragmatically for acceptable solutions to problems their clients present. However, the learning potential of these processes is less well exploited at the system level in education than in medicine.

The key problem is that of horizontal dissemination. Teachers have had few natural incentives to attempt to diffuse their findings either to colleagues in their own school or subject specialism, or to schools elsewhere or to different subject specialists. More and better studies of 'what works' in schools and classrooms could provide a knowledge base, but there is little consensus on the methods that are most appropriate to investigating 'what works', and no system for disseminating outcomes in the form of professional knowledge transfer. There are, of course, some institutional channels that support knowledge flows. Some professional associations work as 'epistemic communities'. Professional journals also play a role in disseminating information about new innovative practices. However, in most countries, professional journals are more like a newspaper than a scholarly journal, and thus do not play a significant role in mediating research evidence to strengthen the knowledge base of teachers. The system in education for innovation and the rapid spread of new ideas and practices is deeply flawed.

\section{Trajectories of Knowledge Production: medicine and education in England}

Whilst different sectors in their current state may lie clearly in one of the four cells in Figure 1 , this ignores the historical development of a sector's knowledge base. Over time a sector may have followed a complex trajectory which, in terms of our model, means that the sector moves cell as its knowledge base changes.

Figure 2 illustrates some trajectories. Note that the arrows indicate the direction of changes, not full migration. Thus the representation of the trajectory of the education sector does not mean that this sector is becoming highly competitive and scientific, with many spillovers. It means that the knowledge base of this sector is in a process of transformation by mixing some features of the scientific mode with the basic features of the humanistic mode, and by introducing some incentives to generate or exploit spillovers. In a similar fashion, medicine has not entirely abandoned the humanistic mode, and indeed may now, at least in some quarters, be strengthening this as the limits of the scientific mode become apparent.

During the nineteenth century the medical profession changed its epistemic culture under the influence of modern science, and this led to the rapid growth and accumulation of medical knowledge that continues to this day. The competition between epistemic 


\begin{tabular}{|c|c|c|}
\hline $\begin{array}{l}\text { Knowledge spillovers } \\
\text { Mode of knowledge } \\
\text { production }\end{array}$ & $\begin{array}{l}\text { Strong spillovers } \\
\text { (competition and/or co- } \\
\text { operation generate } \\
\text { incentives to capture and/or } \\
\text { to reveal knowledge) }\end{array}$ & $\begin{array}{l}\text { Weak spillovers } \\
\text { (lack of competition or co- } \\
\text { operation generates } \\
\text { disincentives to capturing or } \\
\text { sharing knowledge) }\end{array}$ \\
\hline $\begin{array}{l}\text { S-i-T mode } \\
\text { science is in a predictive } \\
\text { stage, formal R\&D is } \\
\text { crucial and knowledge is } \\
\text { highly codified) }\end{array}$ & $\begin{array}{l}\text { Biotechnology, Chemicals, } \\
\text { Transport Technologies }\end{array}$ & Defence equipment \\
\hline $\begin{array}{l}\text { Humanistic mode } \\
\text { (learning-by-doing is the } \\
\text { key process, formal R\&D is } \\
\text { of secondary importance } \\
\text { and knowledge is poorly } \\
\text { articulated) }\end{array}$ & Consulting activity & $\begin{array}{l}\text { Education } \\
\text { (primary school) } \\
\text { Early 19th century } \\
\text { medicine }\end{array}$ \\
\hline
\end{tabular}

Figure 2. Examples of developmental trajectories

cultures among doctors is vividly illustrated in George Eliot's novel Middlemarch. In modern medicine the sub-communities of the various medical specialties fall within the epistemic culture of science; those that do not have the generic name of 'alternative medicine', which demarcates (and perhaps stigmatises) a starkly different epistemic culture. Some branches of psychiatry, under the influence of psycho-analysis and its subsequent development, also stand outside the epistemic culture of science and fall within a humanistic epistemic culture, essentially covering pre-scientific learning-by-doing. It is possible for some members of a community to espouse two epistemic cultures, as when a medical practitioner subscribes to both conventional and alternative medicine, or a psychiatrist admirer of R. D. Laing uses drugs as part of a schizophrenic patient's therapy.

One of the most significant developments in modern medicine has been the randomised controlled trial (RCT), the significance and use of which grew rapidly after its application to tuberculosis in the 1940 s. Today the RCT is widely treated as the evidential 'gold standard' for demonstrating 'what works' and what is medical 'best practice'. In branches of medicine that adhere in whole or part to an epistemic culture of humanism, objections are often raised against the $\mathrm{RCT}$, including ethical reasons.

The developmental trajectory of medicine may thus be described as a movement from a prescientific and relatively non-competitive mode in the nineteenth century into an S-i-T mode that marked the transformation of this community of practice into a scientific epistemic culture (see Figure 2). Competition between doctors is variable. General practitioners have little reason to compete with colleagues, but hospital doctors and consultants at the forefront of their specialty may be as competitive as related industries, such as pharmaceuticals. However, elements of humanistic mode persist, insofar as doctors, in applying science-based medical knowledge to the individual case, see their practice in artistic and humanistic terms. In 1871 the American physician Oliver Wendell Holmes asserted that 'Medicine is the most difficult of sciences and the most laborious of arts' and a century later an English physician, Lord Platt, echoed the sentiment, describing successful diagnosis as a 'skill more closely allied to the skill of a connoisseur examining a picture or old violin than it is to what we normally think of as science' (see Hargreaves et al., 1997). 
In more recent times, during the Thatcher years and subsequently, the NHS in Britain was turned into a more competitive environment. Competition within public sector medicine, as well as between the public and private medical sectors, was encouraged by government in order to promote greater responsiveness to the patient and thereby greater efficiency and effectiveness. Hospitals are subjected to published league tables of the quality of their provision for patients. In our model this policy change should be associated with an increase in involuntary spillovers, given that people and organisations increase their capabilities for adapting and reproducing knowledge generated elsewhere. Hospitals at the lower end of league tables now have an incentive to seek out knowledge for self-improvement.

Education is following a different developmental trajectory. Until the end of the nineteenth century, it was in a non-competitive, pre-scientific state. The application of science to educational problems was much slower than in the case of medicine. Compared to medicine, the results for education in the first half of the twentieth century were disappointing and in some areas led to an abandonment of the scientific mode for educational research. Disputes in the social sciences as a whole, over whether they could or should be essentially science-based, are reflected in the study of education in universities. There is a deep rift between two fundamentally opposed epistemic cultures. On one side stand those who believe it possible to treat medicine as a potential model for the advancement of knowledge in educational practices and who are thus currently inclined to support the application of the RCT to education problems. On the other side stand those who reject this totally and favour the epistemic culture of humanism that has deeply influenced work in the arts and humanities in universities. For this latter group, 'best practice' consists in the judgement, based on depth and breadth of experience, of the individual practitioner as a unique case, and it is achieved through 'reflective practice', a widely used term taken from Schön (1983).

In Britain during the Thatcher era there was a policy of increasing competition between schools, through greater parental choice and information provided to parents about school performance based on the results of tests and examinations, published in 'league tables'. This has led many of the most effective schools to protect their knowledge, for to give it away is to threaten their own advantage over other schools. This emphasis on competition has been maintained since 1997 by the Labour Government, which has been highly favourable to evidence-based policy and practice in education and other areas, in parallel to developments in medicine, with an increased commitment to educational research and its direction. Indeed, the Government established an independent National Educational Research Forum and appointed as its first chairman Sir Michael Peckham, previously the (first) director of Research and Development in the National Health Service. This combination is driving education towards the same destination as medicine in our model, but the route differs, since in this case the introduction of competition precedes the stronger scientific base of R\&D (see Figure 2). The Teacher Training Agency (TTA) has created funds to support teacher-researchers in schools, who in practice work closely with academic researchers in universities. This has been matched by Best Practice Scholarships for teachers, funded by the Department for Education and Skills. The TTA also funds research consortia in which groups of schools and higher education institutions come together to undertake research and development in partnership, with a particular focus on 'what works' in attempts to improve teaching and learning.

This change of direction is also disputed within the academic educationists' community of practice: this is a divided community, not one dominated by the epistemic culture of science with a smaller alternative community that adheres to the culture of humanism. Many academic educationists are deeply hostile to the epistemic culture of science and want to stand alongside groups such as consulting firms with a different notion of 'best practice' and 
how it is defined, accumulated and disseminated. Hammersley (2002), for instance, adheres mainly to a humanistic mode, and whilst he does not deny the possibility of the S-i-T mode of educational research, he insists that the scope is very limited and concludes that current policy is raising expectations of practical applications that can only result in severe disappointment. It is held that government policy is too narrowly focused on short-term and practical ends and that academics are losing their rightful control over the research agenda. Though the National Education Research Forum does not fund research directly, but seeks to broker better coordination between the wide variety of agencies that do fund educational research, it is accused by some academics of unacceptable centralisation and control. Whilst there are signs that its role is being accepted by many professional researchers as broadly positive and constructive, the diverse attitudes towards the Forum betray the deep division among researchers.

In medicine, general practitioners or family doctors share a broad commitment to the epistemic culture of science with the intellectual leaders in higher education, medical schools and teaching hospitals. In primary and secondary education, by contrast, teachers in schools remain largely ignorant of, and entirely indifferent to, the battles between competing epistemic cultures among the schools of education which conduct research and control the initial training of teachers. Sometimes their inclination is to favour the humanistic mode of research, for here they are less intimidated by their lack of research expertise. Generally, however, they are free from pressure to take sides on issues of epistemic culture and can, like practising doctors, find ways of combining the scientific and epistemic cultures in their day-to-day practice.

The growth of the S-i-T mode in educational research in England, when combined with the increased competition between schools, will in our view generate knowledge spillovers that support innovation. Yet for both modes of knowledge production there are substantial problems of dissemination and knowledge transfer in the field of education. The academic journals through which academic researchers report to one another are little understood or used by the vast majority of practising teachers and as yet there is no popular publication through which they can gain access to the latest research. In any event, the dissemination is often better undertaken through face-to-face interaction between researcher and practitioner, a mode of knowledge transfer that can handle the tacit elements involved. In this regard some recent reforms in England are likely to have a significant impact on how innovations are disseminated. Major examples are the newly established Beacon Schools, which produce evidence of exemplary practice in some areas and are then funded to disseminate it to other schools, as well as Specialist Schools, which develop expertise in a curriculum area and then enter partnerships with other schools to disseminate best practice. This development complements the competitive relationship between schools - for students and for funding, as established in the Thatcher period-with a new focus on collaboration and partnership. This is supported by a strong trend in the shape of initial teacher training towards school-based and school-led training, with a consequent reduction in the time trainee teachers spend in higher education. One effect has been to enhance the role of practising teachers as mentors and coaches - the very skills that are vital to knowledge transfer when knowledge is tacit. Finally, the new National College of School Leadership is setting up a series of networked learning communities among schools, which will be a powerful instrument for developing new forms of dissemination and knowledge transfer. These are likely to be key partners of the new Innovation Unit within the Department for Education and Skills, which has been operating since autumn 2002.

At present it seems unlikely in Britain that one of the two epistemic cultures will prevail in university-based study of education or among the rapidly growing, if still relatively small, body of teacher-researchers. The teaching profession's community of practice will thus not 
subscribe to one dominant epistemic culture, as in the case of medicine, but will come to share elements of both epistemic cultures in a new synthesis of practice that selects and blends elements of both. We hypothesise that there will be pressures towards such a synthesis because of the current pressures in both cultures to disseminate best practice. The methodology for determining best practice differs between the epistemic cultures of science and humanism. The scientific approach will stress the need for experiments to yield formal and explicit knowledge of 'what works', the action involved being carefully specified and disseminated through written and visual media (articles, books, videos, etc.). The humanistic approach will identify best practice as embodied in outstanding practitioners who will disseminate their tacit knowledge and practice through modelling, mentoring and coaching. The most discussed method of dissemination - networking - is common to both epistemic cultures. Through the shared commitment to innovation of networking systems, the two cultures may begin to integrate as they impact upon and influence the practices of teachers in schools. Networking involves a complex admixture of collaboration and competition, as the work of Saxenian (1994) on the success of Silicon Valley shows. We therefore hypothesise that in the education sector achieving the highest form of knowledge production, application and dissemination will require policies that promote this combination of competition and collaboration, not competition alone.

\section{Conclusion}

Our model of the growth of knowledge production and dissemination allows a more sophisticated and useful comparison between sectors than has hitherto been usual, and includes the construction of hypotheses, both of developments in England as discussed above, and of developments in other countries where the conditions may be very different. The model should help to analyse the different trajectories that educational research follows in different countries.

As for developments in England, we believe that both modes can be maintained within educational research, and hypothesise that the boundaries between them will, in practice, become highly permeable. The growth in the number of teacher-researchers will, in our view, play a key role in ensuring that a balance is kept, and some integration is achieved, between the two modes. Both modes, especially where they are used in combination by teacher-researchers, will lead to the increase in spillovers that will stimulate further innovation. We do not believe that the growth of knowledge will be as fast as in medicine, because in our view for the immediate future the humanistic mode will retain ardent adherents and the S-i-T mode will take many years before its strengths can be fully demonstrated. In particular, we point to the continuing difficulty of coordinating large numbers of small-scale, practice-based investigations so that they accumulate to a robust corpus of knowledge. But in 1850 nobody could have predicted how medicine was to be transformed over the following hundred and fifty years. Long-term predictions for the future of education are no less hazardous.

Correspondence: Professor Dominique Foray, CERI, OECD, 2 rue Andre Pascal, 75016 Paris, France.

\section{References}

Allen, R. (1983) Collective invention, Journal of Economic Behaviour and Organisation, 4, 1-24.

Appleyard, M. (1996) How does knowledge flow? Inter-firm patterns in the semi-conductor industry, Strategic Management Journal, 17, 137-154. 
Cockburn, I. \& Henderson, R. (1997) Public-private interaction and the productivity of pharmaceutical research, Working paper Series, $n^{\circ} 6018$, NBER, Cambridge, MA.

Cowan, R., David, P.A. \& ForaY, D. (2000) The explicit economics of knowledge codification and tacitness, Industrial and Corporate Change, 9, 2, pp. 211-253.

Dasgupta, P. \& David, P.A. (1994) Towards a new economy of science, Research Policy, 23, 5.

David, P. \& Foray, D. (1995) Accessing and expanding the science and technological knowledge base, STI Review, $\mathrm{n}^{\circ} 16$, Paris, OECD.

Eraut, M., Alderton, J., Cole, G. \& Senker, P. (1998) Learning from other people at work. In: F. Coffield (ed.) Learning at Work, Bristol, The Policy Press.

Fitz-Gibion, C. (2001) What's all this about 'evidence'? Learning and Skills Research, Autumn, $30-33$.

Foray, D. \& Lundvall, B.A. (1996) From the economics of knowledge to the learning economy. In: D. Foray \& B.A. Lundvall (eds) Employment and Growth in the Knowledge-based Economy, Paris, OECD.

Gibbons, M., Limoges, C., Nowotny, H., Shwartzman, S., Scott, P. \& Trow, M. (1994) The New Production of Knowledge, London, Sage.

Hammersley, M. (2002) Educational Research, Policymaking and Practice, London, Paul Chapman.

Hargreaves, D.H. (1999a) Schools and the future: the key role of innovation. In: Innovating Schools, Paris, OECD.

Hargreaves, D.H. (1999b) The production, mediation and use of professional knowledge among teachers and doctors: a comparative analysis. In: Knowledge Management in the Learning Society, Paris, OECD.

Hargreaves, D.H. (1999c) Revitalizing educational research: past lessons and future prospects, Cambridge Journal of Education, 29, 2, 239-249.

Hargreaves, D.H., Southworth, G.W., Stanley, P. \& Ward, J. (1997) On-the-job Training for Physicians, London, Royal Society of Medicine Press.

Harhoff, D., Henkel, J. \& von Hippel, E. (2000) Profiting from Voluntary Information Spillovers: how users benefit by freely revealing their innovations, MIT Sloan School of Management.

Hegarty, S. (1999) Characterizing the knowledge base in education, paper prepared for the OECD-CERI/NSF conference on knowledge indicators, Washington.

Huberman, M. (1992) Teacher development and instruction mastery. In: A. Hargreaves \& M. Fullan (eds.) Understanding teacher development, London, Cassell/Teachers College Press.

JACKson, P.W. (1968) Life in Classrooms, New York, Holt, Rinehart \& Winston.

Knorr Cetina, K. (1999) Epistemic Cultures, Cambridge, MA, Harvard University Press.

Lave, J. \& Wenger, E. (1991) Situated Learning: legitimate peripheral participation, Cambridge, Cambridge University Press.

LorTiE, D. (1975) Schoolteacher, Chicago, IL, University of Chicago Press.

Nelson, R. (1999) Knowledge and innovation systems, in: Knowledge Management in the Learning Society, Paris, OECD.

Nightingale, P. (2000) Physics on Wall Street: Science, Risk and System's Control, CoPS Centre, SPRU, University of Sussex.

OECD (2000) A New Economy? The Changing Role of Innovation and Information Technology in Growth, Paris, OECD.

OECD/CERI (1999) Innovating Schools, Paris, OECD.

Plotkin, H. (2002) The Imagined World Made Real, London, Allen Lane.

SaXenian, A. (1994) Regional Advantage: culture and competition in Silicon Valley and Route 128, Harvard University Press, Cambridge, MA.

Schön, D.A. (1983) The Reflective Practitioner, New York, Basic Books.

SPERBER, D. (1996) Explaining culture, Oxford, Blackwell. 
Teddlie, D. \& Reynolds, D. (eds) (2000) The International Handbook of School Effectiveness Research, London, Falmer Press.

TYre, M.J. \& von Hippes, E. (1997) The situated nature of adaptive learning in organizations, Organization Science, 8, 1.

Wenger, E. (1998) Communities of Practice: learning, meaning and identity, Cambridge, Cambridge University Press. 